\title{
GAPS AND DRAINS
}

Transatlantic confusion persists about two fashionable myths-the technology gap and the brain drain. British parliamentary records are now thick with references to them. In the United States, Mr. Hornig's committee on the subject is presumably hard at work, although very little has been heard of it since its precipitate creation some months ago. Mr. McNamara has had his say about the causes of the brain drain (see Nature, 213, 851; 1967), as have a host of public speakers on both sides of the Atlantic. In Britain, certainly, there is now such a healthy willingness to recognize that the problem is two-sided, and that the loss by emigration to the United States is compensated for in part at least by immigration from elsewhere, that a good deal of bitterness has gone out of the argument.

At the same time, the causes of migration are being more openly recognized. People move because they want to be better off in some sense or another. Sir Solly Zuckerman acknowledged this earlier in the week, and quite properly went on to say that diagnosis is a good deal easier than cure. But if countries in Europe are growing to recognize that the imbalance between the United States and the less prosperous nations of Western Europe, like the imbalance between Western Europe and the rest of the world, is a problem in sociology, other interested parties have yet to be convinced. Mr. McNamara, for example, was too quick to hint that if Britain paid more attention to education, everything would be well. The much respected Business Week (April 8, page 165) has an even more unpalatable statement of what should be done in its statement that "the technology gap arises because the Europeans seem unable to learn the lessons of U.S. industrial progress".

Some of these issues may eventually be sharpenedbut probably not resolved-by a statement earlier this week by Professor Richard Titmuss of the London School of Economics. He was concerned to argue that nations which embark on social welfare programmes of various kinds have an inherent duty to provide the means for attaining them. In this context, the immigration of doctors into the United States was for him only an illustration that the United States is asking for a higher standard of medical care than it is able and willing to support by the training of doctors. Professor Titmuss's speech has been widely quoted for the figure of $\$ 4,000$ million which he estimates it would otherwise have cost to train the 100,000 doctors entering the United States since 1949. The implication, he says, is that this foreign aid to the United. States exceeds the total of the foreign aid in medicine provided by the United States to countries abroad. He speaks of the migration of skilled people as a transfer of human capital-and then quite properly acknowledges that Britain has been doing the same for a very long time. Inevitably, however, the conclusion is that "richer countries should take action to protect the poorer countries from being denuded of skilled manpower". The responsibility lies with the recipients, not the donors.

But there are limits to the extent to which nations can require their citizens to put the national interest first in choosing somewhere to live and some profession in which to work. Professor Titmuss has probably done a valuable public service by broadening the basis of the discussion of the brain drain, and much of what he says applies elsewhere as well. Unfortunately, however, there is no real prospect of much help from administrative devices of the kinds to which his arguments lead. It is therefore lucky that western Europe may well be able to redress the transatlantic imbalance by pursuing vigorously the economic policies on which it has embarked.

\section{POLYTECHNICS}

THE announcement that the Department of Education and Science has nominated two more technical colleges as embryos for polytechnics (see page 229) is another proof that the Government will not be deflected from its declared policy of developing what it calls a comprehensive system of higher education complementary to the university system. Moreover, it now seems that the Government will be successful in what it plans to do. Technical colleges, encouraged by the Robbins Report to think they might become universities any day, have now swallowed their pride, and are by all accounts keen to become polytechnics instead. By September they will have had to satisfy the Government that their plans for self-administration will assure academic independence and integrity. Although there is unlikely to be an immediate change in the character of the chosen institutions, they will from the beginning be more independent of the local authorities which finance them and more able to grow academically.

But what will they become? In the best traditions of contemporary pragmatism, the Government seems to be hoping for the best and for as little trouble as possible. There is no doubt, of course, that the poly. technics will continue to provide a valuable higher education for a growing number of students-the scramble, after the universities have shut their doors each autumn, to find places at which to read for degrees is proof enough of that. When the polytechnics have more independence they will be even more sought 